\title{
Financial calculations on the net
}

\author{
Wolfgang Härdle and Stefan Sperlich \\ Institut für Statistik und Ökonometrie, \\ Wirtschaftswissenschaftliche Fakultät, \\ Humboldt-Universität zu Berlin, \\ D 10178 Berlin
}

June 3, 1997

\section{Introduction to XploRe}

XploRe is an interactive statistical computing environment ${ }^{1}$. As the name indicates, support for exploratory data analysis, for simulation and intensive calculation scenarios is given by a variety of interactive tools. Like most of the statistic software packages it is based on vector- and matrix calculation, but unlikely many such packages, in XploRe matrices can be of up to nine dimensions. Further, XploRe offers extraordinary opportunities in dynamic and interactive graphics.

For our purpose, that is calculating in finance, the interactivity of the user interface and the techniques of visualization are of special importance; particulary since this interactivity is net based and easy to implement for programmers who want to modify or extend existing methods.

*** Figure 1 about here ${ }^{* * *}$

\footnotetext{
${ }^{1}$ This work was supported by the Sonderforschungsbereich 373 "Quantifikation und Simulation Ökonomischer Prozesse" at Humboldt-University, Berlin
} 
A noteworthy quality in XploRe are the capabilities of network facilities, which in software development have become more and more important. From the very beginning, XploRe was geared towards inter- or intranet compatability. Thus, for example, the help system is available in HTML. Furthermore, the newly developed Java interface endows the user with the possibility to work with XploRe via inter- or intranet and thus without the necessity of installing it locally. Thus, a complete session can be opened just with a freely available WWW browser like Netscape (try the http address: http://wotan.wiwi.huberlin.de/xplore/).

\section{The finance library of XploRe}

There is growing interest in quantifying and simulating economic processes, particulary in the statistical analysis of the behaviour of financial markets. The library finance is designed for this purpose. It offers macros to predict and estimate (time series) processes, for example stock returns, to determine option prices and to evaluate different scenarios (e. g. for portfolio strategies).

To give a brief overview of this library we will present and illustrate some macros implemented in finance. It is called by library ("finance") on the free Java interface of XploRe. We will pay special attention to the simulation of processes of stock returns.

\section{The elements of finance}

The basic method to determine option prices of the European kind is to use the analytic solution of Black and Scholes. Their formula allows to calculate the option price under strong assumptions on the model. The analogue for American options is the approximation by McMillan.

Distributions of dividends for assets like stocks usually lead to changes in the value of the corresponding derivative. Unfortunately this often can not be taken into account in the analytic solutions and thus has to be done numerically for European as well as for American options. Therefore binomial trees are used.

These thechniques can be performed interactively via the macro optstart(), as presented in figure 2 for illustration. 
*** Figure 2 about here $* * *$

It is also of interest to investigate and to visualize the influence of the various factors such as domestic interest rate, time to expiration on option prices. This can be done by the macro influence(). Figure 3 displays the surface of option prices versus exercise price and time to expiration while keeping all the other parameters fixed.

Obviously, scenarios for portfolios strategies like the construction of spreads or arbitrage possibilities can easily be obtained by table calculation.

\section{*** Figure 3 about here $* * *$}

It has long be recognized that stock returns do not obey a simple Wiener process. Various alternatives have been introduced, including among others, jump processes or a mixture of Wiener and jump processes, see for example Streller (1995). Macros for simulating such processes and for estimating the parameters in those models are also available, e. g. stocksim(), stockest().

A different approach to model stock prices is using typical time series models such as ARCH, GARCH, EGARCH, T-ARCH and etc., see Gourieroux (1997).

The class of ARCH models, built upon the concept of stochastic volatility, is much more flexible than classic models in fitting financial data. In particular, the time discrete model of Duan (1995) using the GARCH $(1,1)$ process is appealing for the theory of option pricing.

A crucial question is the correct specification of the stochastic volatility. Therefore it is necessary to develop programs to model the volatility more flexible, e. g. , for asymmetry of shocks. Examples of such a development are the Threshold ARCH model of Rabemananjara and Zakoian (1993) and the extension of it to T-GARCH by Härdle and Hafner (1997). The program to analyse and compare these models is implemented, in $\operatorname{tgarsim}()$.

\section{*** Figure 4 about here ${ }^{* * *}$}


In Figure 4 we present results of a comparison of GARCH and T-GARCH to the Black and Scholes option pricing model. Displayed are the generated processes, option prices, absolute and relative differences to Black and Scholes versus moneyness ( $\mathrm{S} / \mathrm{K}$ with $\mathrm{S}=$ stock price, $\mathrm{K}=$ strike price). The greyish curve indicates the T-GARCH model.

All programs are available on the net.

\section{Literatur}

[1] Duan, J. C.: The GARCH option pricing model, Mathematical Finance. 5 (1995) 13-32

[2] Gourieroux, C.: ARCH Models and Financial Applications, Springer Verlag, Heidelberg \& Berlin. (1997)

[3] Härdle, W. , Hafner, C.: Discrete Time Option Pricing with Flexible Volatility Estimation, forthcoming. (1997)

[4] Rabemananjara, R. , Zakoian, J. M.: Threshold ARCH Models and Asymmetries in Volatility, Journal of Applied Econometrics. 8 (1993) 31-49

[5] Streller, A.: Modellierung von Aktienkursen durch Diffusionen mit Sprüngen - Modelldiskussion und ein Weg zur Schätzung der Parameter, Discussion Paper 56., sfb 373. (1995) 


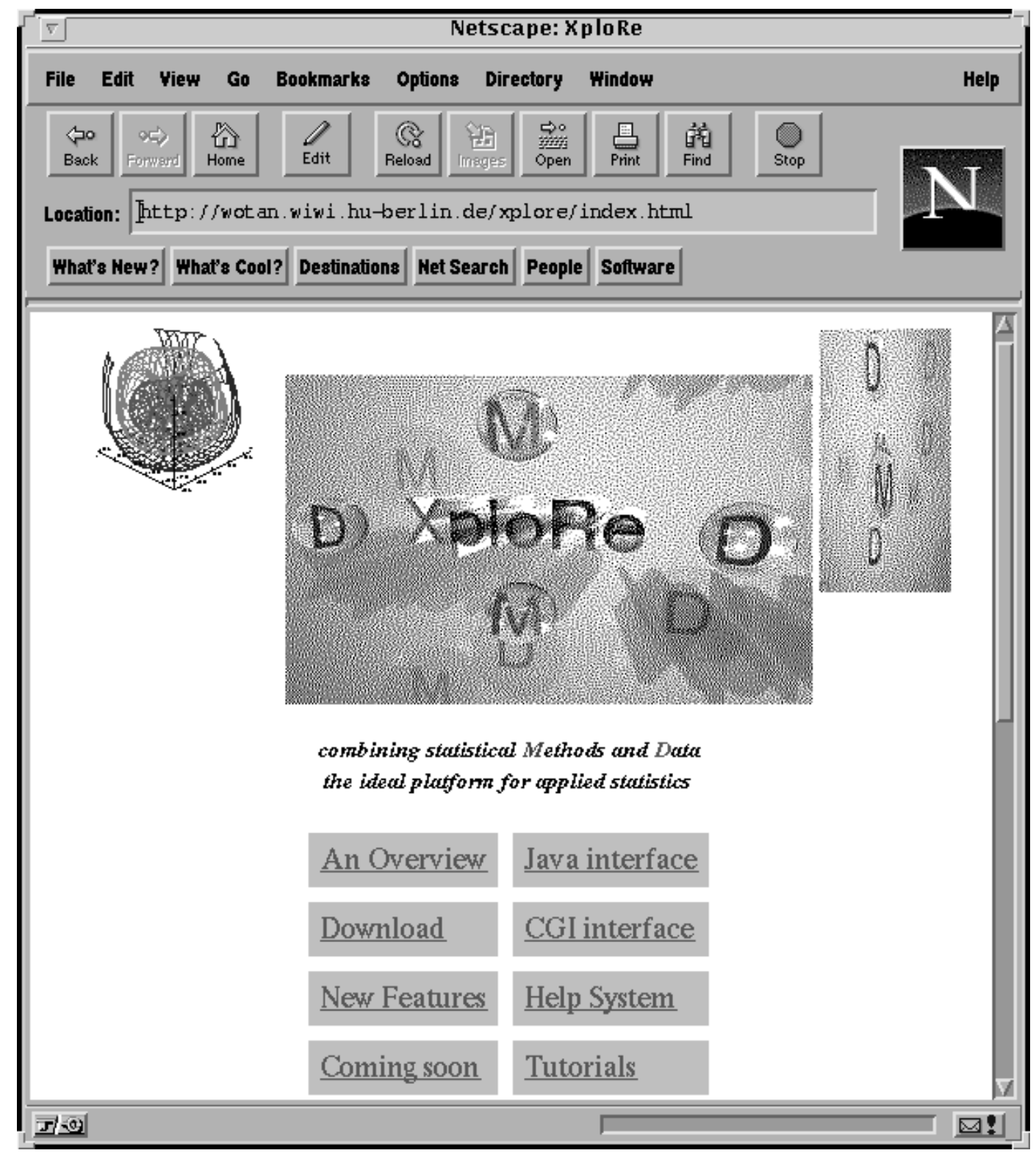

Abbildung 1: WWW page of XploRe 


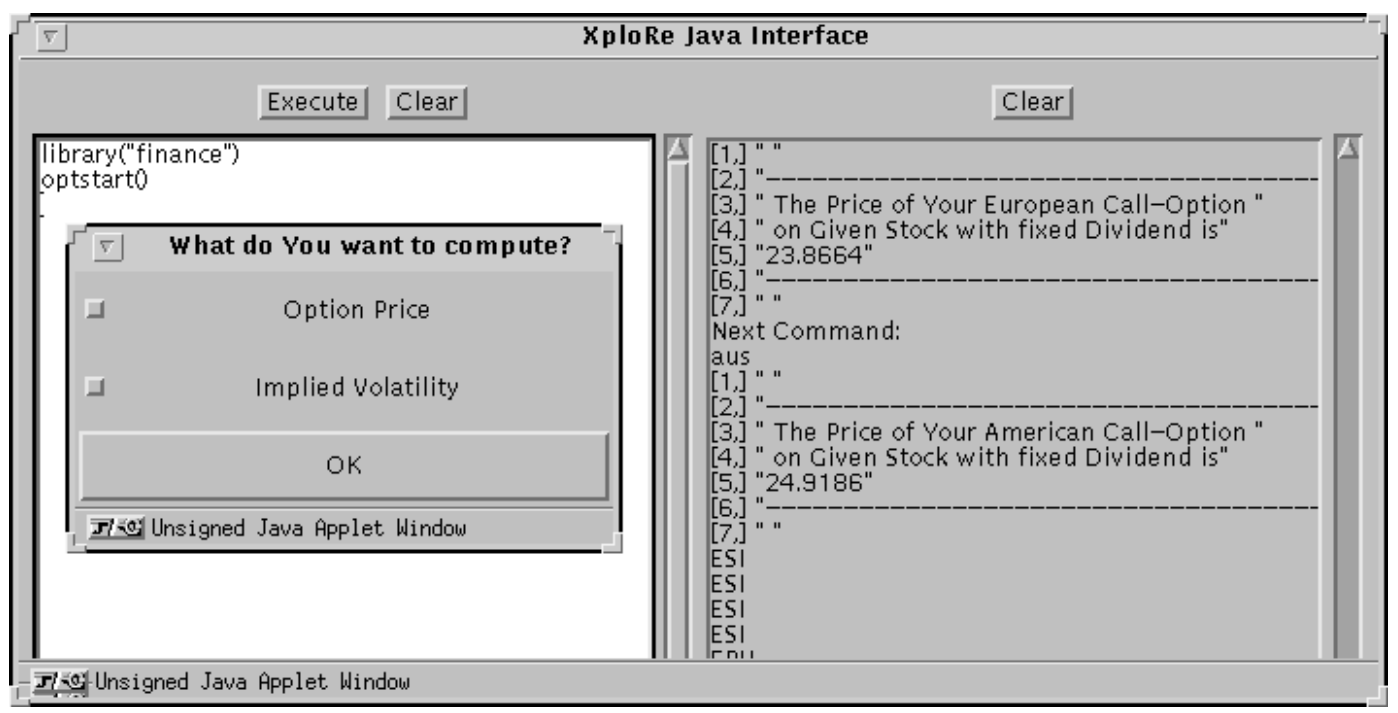

Abbildung 2: The macro optstart running on Java

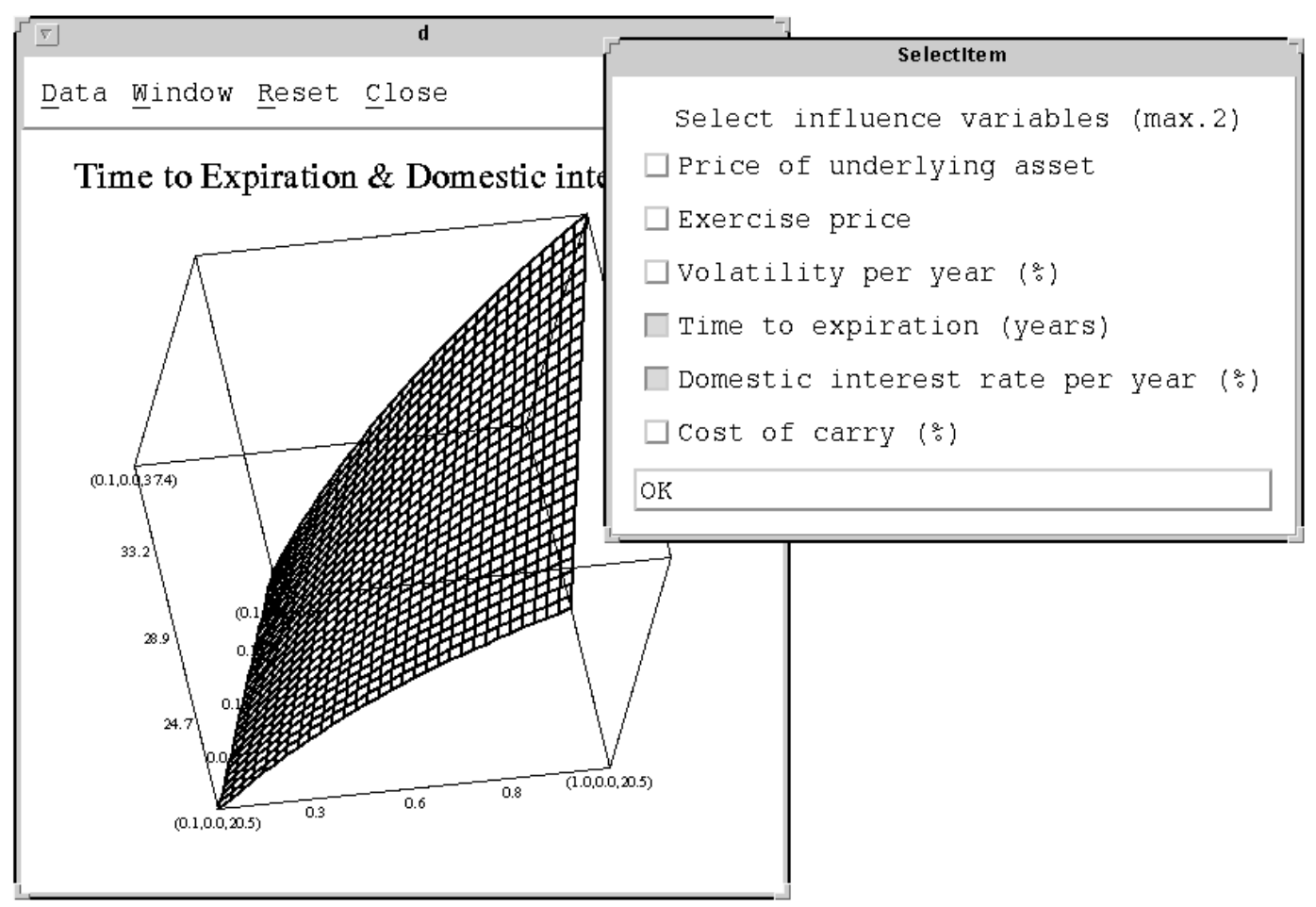

Abbildung 3: The macro influence in action 


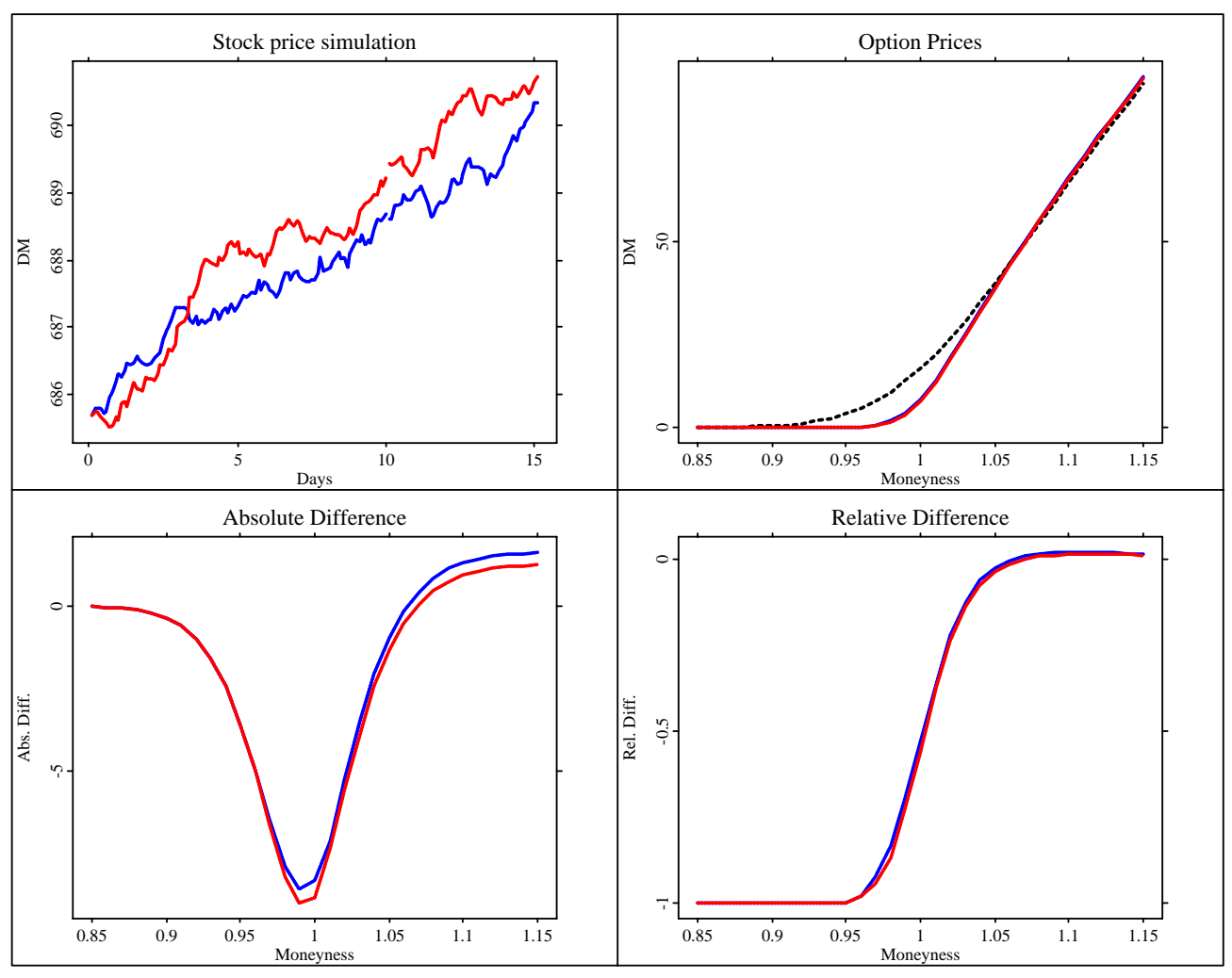

Abbildung 4: The result of the macro tgarsim 